\title{
Effect of Short-Term Intervention Program on Academic Self-Efficacy in Higher Education
}

\author{
Ofra Walter, Vered Shenaar-Golan, Zeevik Greenberg \\ Tel Hai Academic College, Upper Galilee, Israel \\ Email: ofrawa@telhai.ac.il
}

Received 14 June 2015; accepted 2 August 2015; published 5 August 2015

Copyright (C) 2015 by authors and Scientific Research Publishing Inc.

This work is licensed under the Creative Commons Attribution International License (CC BY). http://creativecommons.org/licenses/by/4.0/

(c) (i) Open Access

\begin{abstract}
The current study examines the academic self-efficacy of students at risk for attrition in higher education in the north of Israel. The students participated in the STIC (Short-Term Intensive discipline Courses) program also called "learning marathons", offered in their compulsory subjects in preparation for final exams. The study examined the conditions required for success with academic tasks according to the following variables: academic self-efficacy, emotional intelligence abilities, and coping with stress. The research population included 132 students whose admissions scores ranged between $-\mathbf{1 0} \%$ to $+\mathbf{1 0} \%$ from the minimum score required by the Departments of Science and of Humanities and Social Sciences. Research instruments included four questionnaires: Academic self-efficacy questionnaire, self-reporting emotional intelligence questionnaire, stress appraisal coping questionnaire, and demographic questionnaire. A correlation matrix was created for the difference between the data before and after participation in STIC. The results indicate that short-term intensive support learning that is carried out in small groups and taught by experienced teachers significantly reduces student attrition rates. Moreover, the courses promoted the development of emotional intelligence, enhanced the sense of academic self-efficacy, and advanced the use of coping strategies among students.
\end{abstract}

\section{Keywords}

STIC Program, Higher Education Attrition, Academic Self-Efficacy, Emotional Intelligence Abilities, Coping with Stress

\section{Introduction}

Student academic achievements have always been a major concern of educators and researchers in higher edu- 
cation (Walsh, Larsen, \& Parry, 2009). Of particular concern are issues relating to success and attrition from college or university (Bandura, 1986, 1991). General academic success in Israel is predicted by the "Sechem" score (a combination of high school matriculation and psychometric exam grades), a predictor similar to that used in North America and other Western societies (Sternberg, 2010, 2012; Sternberg, Bonney, \& Gabora, 2012). This predictor, however, overlooks other factors important for academic success.

Research studies have indicated that in order to cope with academic studies, developing emotional abilities is as important as developing students’ cognitive abilities (Morris-Rothschild \& Brassard, 2006). The different components influencing emotional ability to cope with academic studies include academic self-efficacy, emotional intelligence, stress, appraisal and coping strategies, and social surroundings (Bandura, 1986, 1997, 2006; Bandura et al., 2003; Brackett \& Mayer, 2003; Brackett, Rivers, \& Salovey, 2011; Chan, 2004; Folkman \& Moskowitz, 2004; Lazarus \& Folkman, 1984; Mayer, Roberts, \& Barsade, 2008; Morris-Rothschild \& Brassard, 2006). Studies have indicated the need to develop academic support programs that increase academic success and focus on and promote retention. Understanding or lack thereof of these issues impacts positively or negatively on student success (Walsh et al., 2009). The literature describes a variety of academic support programs to meet these key challenges, including tutors and peer support for different courses (Walsh et al., 2009) and a variety of support services for problems related to testing, management of time and instructional materials, and course remediation, particularly during the first two years of study (Lyons et al., 2010). In addition, programs for help coping with general stress and anxiety are offered across the academic years (Lyons et al., 2010; Paul, Hinman, Dottl, \& Passon, 2009). Generally, students who participate in academic support programs have better indicators for succeeding in higher education and completing their degree (Navarrete, Candia, \& Puchi, 2013).

This research study assessed the academic abilities of higher education students throughout their participation in short-term intervention discipline courses (STIC). Similar to other academic support programs, the goal of the STIC program is to improve students' cognitive and emotional intelligence capabilities. The uniqueness of the STIC program is that it is an intensive program implemented just prior to exam period, which emphasizes exam coping skills for students in danger of attrition. The first year of college is a critical year, when the risk of attrition is greatest. This risk is due to three primary factors: 1) first-year students lack the skills, tools, and strategies for academic learning; 2) introductory courses require the mastery of many fundamental terms; and 3) introductory courses are large, limiting the opportunity to ask questions in class and for instructor contact in general. From the data on attrition rates for the last three years at Tel Hai College in northern Israel, where this study was conducted, we see that attrition rates for students who did not participate in STIC courses ranged from $7.1 \%$ $7.8 \%$, compared to a range of $2.5 \%-3.2 \%$ for students who participated in the current study (see Results Table 14).

\section{Literature Review}

\subsection{Academic Self-Efficacy}

Studies have indicated that self-efficacy exerts a proximal effect on academic achievement and other related motivational constructs, such as mastery goals and critical thinking (Phan, 2012). Bandura (1997, 2006) defined student self-efficacy as the student's faith in his or her personal skills required for performing specific learning tasks. Self-efficacy develops gradually over a continual learning process during which a person collects information from varied sources regarding his or her abilities in different fields (Bandura, 1986). This process includes experience implementing the same or similar tasks, observation, verbal persuasion by a reliable individual experienced in the field of the relevant task, and physiological arousal that includes bodily signs such as sweating, trembling, and increased pulse. The significance of these signs is derived from the selective interpretation of the person. This feeling of self-efficacy, that develops gradually, is also significant for coping with learning in higher education (Schunk, 1987; Wigfield \& Eccles, 2000).

Academic self-efficacy has been found to be connected to key concepts in the area of learning motivation, namely, self-perception, optimism, achievement and goal orientation, test anxiety, random attribution, and sense of worthiness (Bates \& Khasawneh, 2007; Hutchison, Follman, Sumpter, \& Bodner, 2006). Therefore, there is considerable importance in developing a sense of academic self-efficacy in students, and in instilling the understanding that developing their emotional abilities, such as coping with stress (Bandura et al., 2003; Cervone, Kopp, Schaumann, \& Scott, 1994), is of equal importance to the development of their cognitive abilities (Britner \& Pajares, 2006; Fenollar, Román, \& Cuestas, 2007; Liem, Lau, \& Nie, 2008; Phan, 2012). Students who dem- 
onstrate a high sense of academic self-efficacy evaluate their academic work as more efficient and effective and solve problems more successfully. Moreover, their perseverance ability is higher than that demonstrated by students with a low sense of academic self-efficacy. They also work more effectively toward accomplishing their tasks. They criticize their work more frequently and implement self-regulation strategies that result in their improved success (Britner \& Pajares, 2006; Fenollar et al., 2007; Liem et al., 2008; Phan, 2012).

\subsection{Stress and Coping Strategies in Higher Education}

Entering higher education is considered one of the most important changes and challenges in the life of the individual (Scott, 1998), forcing a person to cope with an array of pressures such as psychological stress and anxiety (Wintre, Yaffe, \& Crowley, 1995). Stress is defined as a situation in which an individual faces demands that are higher than the resources at his or her disposal (Folkman \& Lazarus, 1986). The term “demands” is subjective with regard to individuals' perceptions of the pressures they face. Stress causes disruption in the personal balance of the individual. The longer the disruption continues and the greater it is, the stronger the feeling of personal stress. This feeling will lessen when the individual and/or someone in his or her environs takes action enabling restoration of the feeling of balance. It is more difficult to restore balance if a gap exists between demands and abilities. Such a gap is likely to damage the feeling of personal comfort or self-esteem (for example, fear of failing an exam or failing at assigned tasks).

Coping strategies employed to lower stress are shaped by a student's personality traits, which, in turn, are discernible in the response itself. The response to stress is also affected by social, economic, and personal resources available to the individual at the time. Appraisal and coping strategies may include behavior, thoughts, and perceptions. They are defined as the constant effort to deal with internal and/or external demands that are perceived as burdening an individual's resources (Lazarus \& Folkman, 1984). Selye (1974, 1976) added that effective coping with extended stress is dependent upon the ability of the individual to assemble numerous additional resources. Assembling resources focuses on one of two strategies. The first is problem-focused, relating to behavioral efforts and involving the active behavior of the individual. The second is emotion-focused, relating to behaviors intended to reduce emotional pressures and is based upon emotional abilities and skills.

\subsection{Emotional Intelligence}

Emotional intelligence (EI) is defined as the ability to identify and understand the emotions that influence us and to use them for coping with ourselves, with others and with the pressures and demands of our environs (Mayer \& Salovey, 1997; Salovey \& Mayer, 1989). The theory focuses on the emotional skills that can be developed through learning and experience. At its foundation lay four central abilities: Perceiving is the ability to identify and decipher emotions in facial expressions, pictures, voices, and objects. It is both the ability to identify the emotions themselves and the self-awareness of emotions. Using is the ability to harness emotions for the benefit of cognitive processes such as thinking and problem solving and the use of emotions to carry out a task successfully. Understanding is the ability to understand the language of emotion, the nuances between different emotions (happiness versus ecstasy), and the potential for the development of emotion over time (shock that turns into sorrow and pain). Managing is the ability to control and adjust emotions in accordance with a situation, whether one’s own or others (Mayer \& Salovey, 1997; Salovey \& Mayer, 1989).

Emotions contain information about the relationships of individuals with their surroundings and are likely to be activated when that system of relationships changes (Lazarus, 1991). During social interactions, emotional expressions, both verbal and para-verbal, give over information about the thoughts, intentions, and behaviors of the individual and others (Buck, 1984; Ekman, 1973; Keltner \& Haidt, 2001). Emotional capability, which includes the ability to perceive, use, understand, and manage emotions, contributes to optimizing social functioning (Denham et al., 2003; Eisenberg, Fabes, Guthrie, \& Reiser, 2000; Feldman, Philippot, \& Custrini, 1991; Nowicki \& Duke, 1994; Savage, 2002). Thus, for example, precise apprehension of the emotions of the individual (according to type and strength) enables prediction and understanding of the individual's subsequent actions. In their research, Elfenbein, Marsh and Ambady (2002) and Damasio and Carvalho (2013) claimed that effective coping with emotionsprecedes effective coping and using... [of] the necessary skills in academic studies. Intelligent processing and efficient managing of emotional information are required to navigate in the social and academic world (Keltner \& Kring, 1998). On the other hand, those laboring in the field of teaching are required, as well, to respond to the emotional needs of learners coping with the pressures arising during their studies 
(Hochschild, 1983; Kremenitzer, 2005; Sutton \& Wheatley, 2003).

\section{Method}

The current study examined the academic self-efficacy of at risk for attrition students in higher education in the north of Israel, who participated in short-term intervention discipline courses offered in their compulsory subjects (STIC, also called "learning marathons"). The general research hypothesis was that the students who participate in STIC will lower their risk for attrition and develop academic self-efficacy. The study examined the conditions required for success with academic tasks according to the following variables: academic self-efficacy, emotional intelligence abilities (EI), coping with stress, admissions scores, and year of study.

\subsection{Research Hypotheses}

1) Participation in the "STIC" program will decrease attrition, increase student academic self-efficacy and EI abilities, and improve coping strategies.

2) Differences will be found between first, second, and third-year student academic self-efficacy and EI abilities as a result of their participation in the "STIC" program.

3) Differences will be found in student academic self-efficacy and EI abilities as a result of participation in the "STIC" program between students with different admissions scores.

4) Higher EI abilities and the presence of effective coping strategies for problem solving will predict student academic self-efficacy.

\subsection{Subjects}

The sample included 132 students (26.4\% female; $65.3 \%$ male) whose mean age was 24 years $(\mathrm{M}=24.2$; $\mathrm{SD}=$ 2.5). The majority of the respondents (63.6\%) were from the Science Department (Nutritional Science, Environmental Science, Food Science and more),with the remainder (36.4\%) from the Department of Humanities and Social Sciences (Social Work, Economics, Psychology, Education and more). Eighty-five \% of the respondents were native Israelis and $94.7 \%$ were single and $3 \%$ were married. Student admissions scores $(M=549.6$; $\mathrm{SD}=74.14$ ), taken from the Examinations Department of the Ministry of Education, fell into the following ranges: $9.6 \%$ of the students had scores under $450 ; 13.8 \%$ ranged from 451 - 500; 24.5\% ranged from 501 - 550; 23.4\% ranged from 551 - 600; 22.3\% ranged from 601 - 650; and 6.4\% had scores of 651 and higher. Fifty-two (42.6\%) were first-year students, 50 (41\%) were second-year students, and 18 (14.8\%) were third-year students. Some of the second-year students also participated in the STIC program in their first year of studies.

\subsection{Research Procedure}

The research population included 132 students who participated in preparatory courses for final exams (STIC). The students' admissions scores ranged between $-10 \%$ to $+10 \%$ from the minimum score required by the Departments of Science, Humanities and Social Sciences. This group was defined as being at risk for attrition. While participation in the learning marathons was voluntary and based upon student desire, students at risk for attrition were recommended to enroll. The marathon program consisted of short courses of up to 12 hours of study in sessions of 2 - 3 hours in length. They were conducted in small groups of 8 - 10 students. Each marathon offered concentrated learning of material and class exercises. Emphasis was placed on review of fundamental terms and understanding and practice of sample exam questions. The courses presented students with a proper learning model that included prior, independent learning of the material by the student, followed by review and practice exercises. The small group framework enabled explanation of unclear material and individual assistance with answering sample exam questions. The learning marathon instructors were teaching assistants who were studying for their M.A. degree and who had a grade point average of over 85 . They had experience teaching and presenting exercises in small groups. In order to evaluate the effect of the intervention, questionnaires were given at the beginning and end of the marathon courses.

\subsection{Research Instruments}

1) Academic self-efficacy questionnaire: The academic self-efficacy questionnaire was developed by Owen 
and Froman (1988) and consisted of 33 statements based upon self-reporting of the respondents. The goal of the questionnaire was to examine the level of academic self-efficacy of the students according to the level of confidence they experienced in different aspects related to academic ability. For example, the respondents were asked to rate their level of confidence "to understand the majority of the ideas they read in a text" (statement \#20) or "to argue with the opinion of the instructor in class" (statement \#27). Respondents were asked to rank the applicability of the statement to them on a scale of $1-4$, with 1 being "at a very low level" and 4 being "at a very high level". Owen and Froman (1988) reported a rate of $92 \%$ reliability of their research findings. The reliability of the questionnaire in this research according to Cronbach's alpha was 0.90 .

2) Self-reporting EI questionnaire: EI was assessed using SREIT (Schutte et al., 1998), a 33-item, self-reporting questionnaire that assesses various aspects of EI based, theoretically, on the four-tier EI model by Mayer, Salovey and Caruso (2000). The 33-item self-reporting questionnaire was based on a five-point scale (1 = strongly disagree to 5 = strongly agree), and assessed three broad dimensions: a) the appraisal and expression of emotions, consisting of 13 items; b) the regulation of emotions, consisting of 10 items; and c) the utilization of emotions, consisting of 10 items. According to Schutte et al. (1998), SREIT has good predictive and discriminant validity and high reliability, with a Cronbach's alpha value $(\alpha)$ of 0.90 . The questionnaire in this research had a Cronbach's alpha value $(\alpha)$ of 0.92 . Examples of SREIT items included: "I am aware of the non-verbal messages I send to others" and "I easily recognize my emotions as I experience them".

3) Stress appraisal and coping questionnaire: The goal of the stress appraisal and coping questionnaire was to measure various patterns of coping used by students when faced with events arousing stress. The questionnaire that was used was developed by Malach-Fines (1984). It included a list of 12 strategies for coping with situations of stress such as: "I try to find positive aspects in the situation"; "I keep myself busy with different activities"; "I ignore the stress". The respondents were asked to evaluate each of the strategies according to the frequency used, on a scale from 1 (rarely) to 5 (frequently). In this study the reliability of the questionnaire according to Cronbach's alpha was 0.69 for coping strategies and 0.60 for avoidant coping strategies.

4) Demographic questionnaire: The demographic questionnaire included details regarding age, gender, department and year in college, status, andadmissions score (see Table 1).

5) Data on attrition rates: Attrition rates were taken from the Examinations Department of the Ministry of Education. The attrition rates for students who participated in the STIC program were compared with those for students with similar admissions criteria who did not participate in the program (see Table 14).

\subsection{Statistical Analysis}

In this research study, several data analyses were made:

1) Correlation matrix between the different research variables at two points in time: before and after participation in the STIC program.

2) T-test Was conducted to test differences between the different research variables at two points in time.

$3)$ An ANOVA analysis In order to test whether differences in coping strategies existed between the years in college $(1-3)$.

4) Regression analysis in the following variables; academic self-efficacy was the dependent variable, and emotional intelligence, use of coping strategies, and use of avoidant coping strategies were the independent variables.

\section{Results}

Before testing the research hypotheses, we created a correlation matrix between the different research variables at two points in time: before and after participation in the STIC program. A strong positive correlation was found between academic self-efficacy and emotional intelligence at both points in time (before $0.416^{* * *}$; after $0.523^{* * * *}$ ). In addition, a positive correlation was found between academic self-efficacy and the use of coping strategies at both points in time (before $0.341^{* * *}$; after $0.471^{* * *}$ ). A clear, positive correlation was found between the use of coping strategies and emotional intelligence abilities at both points in time (before $0.470^{* * *}$; after $\left.0.548^{* * *}\right)$.

Study of Table 2 shows the correlation between the variables of academic self-efficacy, emotional intelligence, use of coping strategies, use of avoidant coping strategies, year of study, and admissions score.

We then created a correlation matrix for the difference between the data before and after participation in STIC. 
Table 1. Demographic variables: gender, age, department of study, family status, admissions score, and year in college.

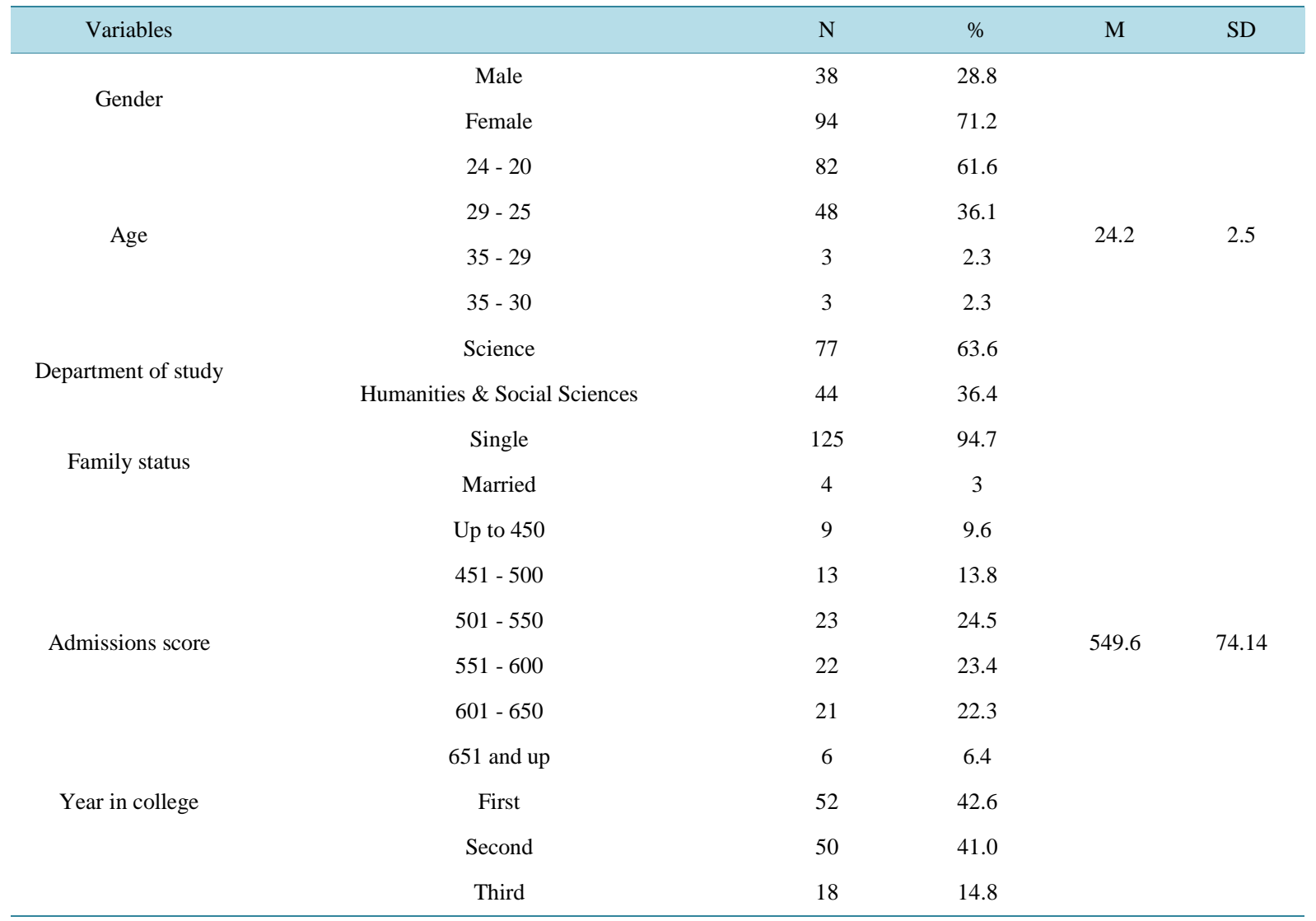

Table 2. Pearson correlation matrix for research variables before and after the marathon $(\mathrm{N}=132)$.

\begin{tabular}{|c|c|c|c|c|c|c|c|c|}
\hline Variables & & 1 & 2 & 3 & 4 & 5 & 6 & 7 \\
\hline \multirow{2}{*}{ 1. Academic self-efficacy } & Before & & $0.416^{* * *}$ & $0.341^{* * *}$ & -0.011 & 0.043 & 0.029 & 0.041 \\
\hline & After & & $0.523^{* * *}$ & $0.471^{* * *}$ & -0.158 & $0.197 *$ & -0.141 & -0.057 \\
\hline \multirow{2}{*}{ 2. Emotional intelligence } & Before & & & $0.470^{* * *}$ & -0.109 & -0.118 & 0.185 & -0.150 \\
\hline & After & & & $0.548^{* * *}$ & $-0.380^{* * *}$ & -0.002 & 0.154 & -0.162 \\
\hline \multirow{2}{*}{ 3. Coping strategies } & Before & & & & $0.179^{*}$ & $-0.297^{* *}$ & 0.078 & -0.121 \\
\hline & After & & & & -0.168 & 0.074 & 0.141 & -0.038 \\
\hline \multirow{2}{*}{ 4. Avoidant coping strategies } & Before & & & & & -0.116 & -0.176 & -0.110 \\
\hline & After & & & & & $0.065^{* * *}$ & -0.079 & -0.041 \\
\hline \multirow{2}{*}{ 5. Year in college } & Before & & & & & & -0.177 & $0.282^{* *}$ \\
\hline & After & & & & & & $0.282^{* *}$ & $0.282^{* *}$ \\
\hline \multirow{2}{*}{ 6. Admissions score } & Before & & & & & & & 0.005 \\
\hline & After & & & & & & & 0.005 \\
\hline
\end{tabular}

${ }^{*} p<0.05, \stackrel{* *}{p} p<0.01, \stackrel{* * *}{p} p<0.001$.

Study of Table 3 demonstrates the relationship between the variables academic self-efficacy, emotional intelligence, use of coping strategies, use of avoidant coping strategies, year in college, and admissions score. The variable academic self-efficacy had strong positive correlation with the variables emotional intelligence and use of 
Table 3. Pearson correlation matrix for the difference between research variables before and after the marathon $(\mathrm{N}=132)$.

\begin{tabular}{ccccccccc}
\hline Variables & 1 & 2 & 3 & 4 & 5 & 6 & 7 \\
\hline 1. Difference-academic self-efficacy & & $0.468^{* * *}$ & $0.267^{*}$ & -0.094 & 0.059 & -0.189 & -0.050 \\
2. Difference-emotional intelligence & & & $0.284^{* *}$ & 0.097 & 0.127 & -0.002 & -0.078 \\
3. Difference-coping strategies & & & & $0.303^{* *}$ & $0.357^{* * *}$ & 0.066 & 0.141 \\
4. Difference-avoidant coping strategies & & & & & 0.074 & 0.126 & 0.016 \\
5. Year in college & & & & & -0.177 & $0.282^{* *}$ \\
6. Admission score & & & & & & & & \\
\hline
\end{tabular}

${ }^{*} p<0.05,{ }^{* *} p<0.01,{ }^{* * *} p<0.001$.

coping strategies, while the variable emotional intelligence had a medium positive correlation with the variable use of coping strategies. Furthermore, it was found that use of coping strategies was found to have strong positive correlation with the year in college, and medium correlation with the use of avoidant coping strategies. Similarly, a medium correlation was found between use of avoidant coping strategies and year in college.

The hypothesis relating to examining the influence of the intervention on the research variables was tested using a paired t-test. A clear difference was found in the use of avoidant coping strategies before the marathon and after $\left[\mathrm{t}_{(85)}=3.51, p<0.01\right]$, such that the average before the marathon was higher $(\mathrm{M}=2.44, \mathrm{SD}=0.075)$ than the average after $(\mathrm{M}=2.22, \mathrm{SD}=0.068)$. The remaining analyses did not yield clear results (See Table 4$)$.

With regard to the differences between academic years 1 - 3 before and after the marathon, (Table 5), the findings indicated that for the first year there was a clear difference (borderline-0.056) for the variable emotional intelligence $\left[\mathrm{t}_{(33)}=1.98, p<0.05\right]$ such that before the marathon the average was higher $(\mathrm{M}=3.83, \mathrm{SD}=0.259)$ than after the marathon $(\mathrm{M}=3.76, \mathrm{SD}=0.39)$. An additional significant variable was the use of strategies for coping with stress $\left[\mathrm{t}_{(33)}=3.26, p<0.51\right]$ for which it was found that the average before was higher $(\mathrm{M}=3.65$, $\mathrm{SD}=0.731)$ than after the marathon $(\mathrm{M}=3.31, \mathrm{SD}=0.584)$. The final variable that was found to be significant was the use of avoidant coping strategies $\left[\mathrm{t}_{(33)}=2.92, p<0.01\right]$, which also had a higher average $(\mathrm{M}=2.55$, SD $=0.756)$ before the marathon than after the marathon $(\mathrm{M}=2.27, \mathrm{SD}=0.586)$. In the second year, only one significant variable was found, that of use of avoidant coping strategies $\left[\mathrm{t}_{(37)}=2.22, p<0.05\right.$ ] such that before the marathon the average was higher $(\mathrm{M}=2.33$, $\mathrm{SD}=0.659)$ than after the marathon $(\mathrm{M}=2.14, \mathrm{SD}=0.642)$. For the third year, emotional intelligence increased after the marathon.

In terms of the differences before and after the marathon between admissions scores (Table 6), it is evident that there was a difference in academic self-efficacy, strategies for coping with stress, emotional intelligence, and avoidant coping strategies between the different admissions scores for which a paired t-test was conducted. For students with admissions scores up to 450, the variable of use of avoidant coping strategies was found significant $\left(\mathrm{t}_{(11)}=2.32, p<0.05\right)$ such that the average before the marathon was higher $(\mathrm{M}=3.13, \mathrm{SD}=0.473)$ than the average after $(M=2.97, \mathrm{SD}=0.16)$.For students with admissions scores in the range of $501-550$ the variable of academic self-efficacy was found significant $\left(\mathrm{t}_{(19)}=2.042, p<0.05\right)$, such that the average before the marathon was higher $(M=2.97, \mathrm{SD}=0.186)$ than the average after $(\mathrm{M}=2.65, \mathrm{SD}=0.379)$. The result was similar for the variable of use of avoidant coping strategies $\left(\mathrm{t}_{(18)}=2.348, p<0.05\right)$, such that the average before the marathon was higher $(\mathrm{M}=2.55, \mathrm{SD}=0.895)$ than the average after $(\mathrm{M}=2.16, \mathrm{SD}=0.616)$. For those in the admissions score range of 601 - 650, the variable of use of avoidant coping strategies was also found to be significant $\left(\mathrm{t}_{(14)}=2.21, p<0.05\right)$, such that the average before the marathon was higher $(\mathrm{M}=2.58, \mathrm{SD}=0.505)$ than the average after $(M=2.3, S D=0.575)$. Moreover, for the range of 651 and above the variable of academic self-efficacy was significant $\left(\mathrm{t}_{(4)}=2.84, p<0.05\right)$, such that the average before the marathon was higher $(\mathrm{M}=$ $2.85, \mathrm{SD}=0.498)$ than the average after $(\mathrm{M}=2.45, \mathrm{SD}=0.752)$.

In order to test whether differences in coping strategies existed between the years in college (1 - 3), an ANOVA analysis was done (Table 7). A significant difference was found between the years $[\mathrm{F}(3,82)=5.19, p$ $<0.05]$. A post hoc analysis using the Sceffe Test found that the highest difference was among students in Year $3(\mathrm{M}=0.210, \mathrm{SD}=0.529)$. This was followed by the differences in Year $1(\mathrm{M}=-0.345$, SD $=0.598)$ and Year $2(\mathrm{M}=0.124, \mathrm{SD}=0.522)$ for whom no significant difference was found between them. Similarly, a larger gap was found to exist among students in Year 2 than in Year 1. 
Table 4. Paired t-test results for examination of the differences in the variables of academic self-efficacy, emotional intelligence, use of coping strategies, and use of avoidant coping strategies before and after participation in the marathon.

\begin{tabular}{|c|c|c|c|c|c|}
\hline Variables & Before/After the marathon & SD & M & $\mathrm{T}$ & Sig \\
\hline \multirow[b]{2}{*}{ Academic self-efficacy } & Before & 0.381 & 2.69 & \multirow[b]{2}{*}{-1.10} & \multirow[b]{2}{*}{0.271} \\
\hline & After & 0.412 & 2.73 & & \\
\hline \multirow{2}{*}{ Emotional intelligence } & Before & 0.342 & 3.83 & \multirow{2}{*}{0.759} & \multirow{2}{*}{0.450} \\
\hline & After & 0.411 & 3.81 & & \\
\hline \multirow[b]{2}{*}{ Coping strategies } & Before & 0.662 & 3.38 & \multirow[b]{2}{*}{0.668} & \multirow[b]{2}{*}{0.506} \\
\hline & After & 0.591 & 3.34 & & \\
\hline \multirow{2}{*}{ Avoidant coping strategies } & Before & 0.704 & 2.44 & \multirow{2}{*}{3.51} & \multirow{2}{*}{0.001} \\
\hline & After & 0.638 & 2.22 & & \\
\hline
\end{tabular}

Table 5. Paired t-test results for examination of differences in the variables academic self-efficacy, emotional intelligence, use of coping strategies, and use of avoidant coping strategies before and after participation in the marathon in relation to the difference in year in college.

\begin{tabular}{|c|c|c|c|c|c|c|}
\hline Variables & Year in college & Before/After the marathon & SD & M & $\mathrm{T}$ & Sig \\
\hline \multirow{6}{*}{ Academic Self-efficacy } & \multirow[t]{2}{*}{ First year } & Before & 0.320 & 2.66 & \multirow[t]{2}{*}{-0.127} & \multirow[t]{2}{*}{0.900} \\
\hline & & After & 0.391 & 2.67 & & \\
\hline & \multirow{2}{*}{ Second year } & Before & 0.414 & 2.65 & \multirow{2}{*}{-0.951} & \multirow{2}{*}{0.348} \\
\hline & & After & 0.400 & 2.71 & & \\
\hline & \multirow{2}{*}{ Third year } & Before & 0.354 & 3.01 & \multirow{2}{*}{-1.29} & \multirow{2}{*}{0.223} \\
\hline & & After & 0.354 & 3.01 & & \\
\hline \multirow{6}{*}{ Emotional intelligence } & \multirow{2}{*}{ First year } & Before & 20.59 & 3.83 & \multirow{2}{*}{1.98} & \multirow{2}{*}{0.056} \\
\hline & & After & 0.390 & 3.76 & & \\
\hline & \multirow{2}{*}{ Second year } & Before & 0.372 & 3.86 & \multirow{2}{*}{-0.179} & \multirow{2}{*}{0.859} \\
\hline & & After & 0.414 & 3.87 & & \\
\hline & \multirow{2}{*}{ Third year } & Before & 0.354 & 3.01 & \multirow{2}{*}{0.342} & \multirow{2}{*}{0.739} \\
\hline & & After & 0.354 & 3.01 & & \\
\hline \multirow{6}{*}{ Coping strategies } & \multirow{2}{*}{ First year } & Before & 0.731 & 3.65 & \multirow{2}{*}{3.26} & \multirow{2}{*}{0.003} \\
\hline & & After & 0.584 & 3.31 & & \\
\hline & \multirow{2}{*}{ Second year } & Before & 0.546 & 3.23 & \multirow{2}{*}{-1.47} & \multirow{2}{*}{0.150} \\
\hline & & After & 0.660 & 3.35 & & \\
\hline & \multirow{2}{*}{ Third year } & Before & 0.354 & 3.01 & \multirow{2}{*}{-1.37} & \multirow{2}{*}{0.196} \\
\hline & & After & 0.354 & 3.01 & & \\
\hline \multirow{6}{*}{ Avoidant coping strategies } & \multirow{2}{*}{ First year } & Before & 0.756 & 2.55 & \multirow{2}{*}{2.92} & 0006 \\
\hline & & After & 0.586 & 2.27 & & \\
\hline & Second vear & Before & 0.659 & 2.33 & 222 & 0032 \\
\hline & & After & 0.642 & 2.14 & & \\
\hline & Third year & Before & 0.354 & 3.01 & 0920 & 0377 \\
\hline & & After & 0.354 & 3.01 & & \\
\hline
\end{tabular}


Table 6. Paired t-test results for examination of differences in academic self-efficacy, emotional intelligence, use of coping strategies, and use of avoidant coping strategies before and after participation in the marathon in relation to the difference in admissions scores.

\begin{tabular}{|c|c|c|c|c|c|c|}
\hline \multicolumn{3}{|c|}{ Admissions score } & \multirow{2}{*}{$\begin{array}{c}\mathrm{M} \\
2.76\end{array}$} & \multirow{2}{*}{$\begin{array}{c}\text { SD } \\
0.440\end{array}$} & \multirow{3}{*}{$\begin{array}{c}\mathrm{T} \\
-0.836\end{array}$} & \multirow{3}{*}{$\begin{array}{r}\text { Sig } \\
0.428\end{array}$} \\
\hline \multirow{10}{*}{$\begin{array}{l}\text { Academic } \\
\text { self-efficacy }\end{array}$} & \multirow{2}{*}{ Up to 450} & Before & & & & \\
\hline & & After & 2.85 & 0.408 & & \\
\hline & \multirow{2}{*}{$451-500$} & Before & 2.76 & 0.264 & \multirow{2}{*}{-0.999} & \multirow{2}{*}{0.340} \\
\hline & & After & 2.83 & 0.355 & & \\
\hline & \multirow{2}{*}{$501-550$} & Before & 2.65 & 0.379 & \multirow{2}{*}{-2.04} & \multirow{2}{*}{0.055} \\
\hline & & After & 2.75 & 0.349 & & \\
\hline & \multirow{2}{*}{$551-600$} & Before & 2.69 & 0.359 & \multirow{2}{*}{0.236} & \multirow{2}{*}{0.817} \\
\hline & & After & 2.67 & 0.429 & & \\
\hline & \multirow{2}{*}{$601-650$} & Before & 2.63 & 0.393 & \multirow{2}{*}{-0.549} & \multirow{2}{*}{0.592} \\
\hline & & After & 2.70 & 0.408 & & \\
\hline & \multirow{2}{*}{651 or more } & Before & 2.85 & 0.498 & \multirow{2}{*}{2.84} & 0046 \\
\hline & & After & 2.45 & 0.752 & & 0.040 \\
\hline & Un to 450 & Before & 3.73 & 0.366 & 0,537 & 0606 \\
\hline & $0 p+040$ & After & 3.68 & 0.380 & 0.357 & 0.000 \\
\hline & & Before & 3.94 & 0.350 & & \\
\hline & $451-500$ & After & 3.89 & 0.401 & $0.6 / 2$ & 0.517 \\
\hline & $501-550$ & Before & 3.69 & 0.237 & -0457 & 0653 \\
\hline Emotional intelligence & $501-300$ & After & 3.76 & 0.303 & $0.4 J 7$ & 0.035 \\
\hline 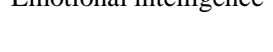 & $551-600$ & Before & 3.89 & 0.274 & -0243 & 0811 \\
\hline & $351-000$ & After & 3.91 & 0.454 & -0.243 & 0.011 \\
\hline & $601-650$ & Before & 3.97 & 0.333 & 0464 & 0650 \\
\hline & $001-050$ & After & 3.92 & 0.492 & 0.404 & 0.030 \\
\hline & 651 or more & Before & 3.80 & 0.640 & 112 & 0323 \\
\hline & 6st or more & After & 3.67 & 0.711 & 1.12 & 0.322 \\
\hline & Un to 450 & Before & 3.39 & 0.456 & 0543 & 0602 \\
\hline & Up to 450 & After & 3.28 & 0.524 & 0.045 & 0.002 \\
\hline & $451-500$ & Before & 3.27 & 0.483 & -0.552 & 0.593 \\
\hline & $401-500$ & After & 3.36 & 0.429 & -0.532 & 0.593 \\
\hline & $501-550$ & Before & 3.19 & 0.692 & 0.416 & 0682 \\
\hline Coping strategies & & After & 3.13 & 0.576 & 0.410 & \\
\hline & $551-600$ & Before & 3.50 & 0.643 & 0812 & 0420 \\
\hline & $551-600$ & After & 3.40 & 0.639 & 0.813 & 0.429 \\
\hline & $601-650$ & Before & 3.57 & 0.881 & -0.130 & 0899 \\
\hline & & After & 3.38 & 0.776 & & \\
\hline & 651 or more & Before & 3.31 & 0.574 & -0.674 & 0.537 \\
\hline & (5J1 or more & After & 3.57 & 0.677 & $-0.6 / 4$ & $0.53 /$ \\
\hline & Un to 450 & Before & 2.80 & 0.877 & 132 & 0.223 \\
\hline & & After & 2.51 & 0.671 & & \\
\hline & $451-500$ & Before & 2.40 & 0.270 & 0.886 & 0396 \\
\hline & $451-500$ & After & 2.27 & 0.627 & 0.000 & 0.390 \\
\hline & $501-550$ & Before & 2.55 & 0.895 & 2.34 & 0.031 \\
\hline Avoidant coping & & After & 2.16 & 0.616 & & \\
\hline strategies & $551-600$ & Before & 2.36 & 0.677 & 0555 & 0587 \\
\hline & $531-000$ & After & 2.31 & 0.719 & 0.353 & $0.30 \%$ \\
\hline & $601-650$ & Before & 2.58 & 0.505 & 2.21 & 0.045 \\
\hline & $001-000$ & After & 2.30 & 0.575 & & \\
\hline & 651 or more & Before & 2.11 & 0.965 & -0.722 & 0.510 \\
\hline & - & After & 2.40 & 0.969 & 0.122 & 0.010 \\
\hline
\end{tabular}


Table 7. ANOVA analysis between coping strategies and year in college.

\begin{tabular}{ccccc}
\hline Variables & Year in college & M & SD & F \\
\hline \multirow{2}{*}{ Coping strategies } & First year & -0.345 & 0.598 & \\
& Second year & 0.522 & 0.124 & 5.19 \\
& Third year & 0.210 & 0.529 & \\
\hline
\end{tabular}

Testing of the research variables succeeded in predicting the sense of academic self-efficacy. Specifically, it was shown that emotional intelligence capabilities, the ability to use coping strategies, and the ability to use avoidant coping strategies before the intervention process predicted academic self-efficacy among students participating in the STIC program. The hypothesis was checked by means of simple regression (Enter). In the regression analysis, academic self-efficacy was the dependent variable, and emotional intelligence, use of coping strategies, and use of avoidant coping strategies were the independent variables. Study of the regression analysis findings shows that the model was found to be statistically significant at the first point in time before the intervention (Table 8). The explained variation is $29 \%$ [F $(9,76=3.39, p<0.001]$. The values of the standardized regression coefficients $(\beta)$ before the intervention process demonstrate that the contribution of emotional intelligence capabilities was significant. Likewise, one can see that emotional intelligence had the strongest influence on the development of academic self-efficacy of the student. Based on the unstandardized regression coefficients, one can see a positive correlation between emotional intelligence and academic self-efficacy, such that the higher the emotional intelligence, the higher the academic self-efficacy.

Study of the regression analysis findings presented in Table 9 shows that the model was statistically significant at the second point in time. The explained variation is $59 \%$ [F $(9,71)=10.06, p<0.001]$. The values of the standardized regression coefficients $(\beta)$ at the second point in time, after a process of intervention, demonstrate that the variables emotional intelligence, use of coping strategies, and admissions scores had a clear ability to predict academic self-efficacy. In addition, one can see that emotional intelligence had the greatest influence, followed by use of coping strategies and then admissions score. According to the unstandardized regression coefficients, one can see that there was a positive correlation between academic self-efficacy with both emotional intelligence and coping strategies, such that the higher emotional intelligence and coping strategies, the higher the academic self-efficacy. Furthermore, a negative correlation was found between admissions scores and academic self-efficacy, such that the higher the admissions score the lower the academic self-efficacy.

From study of the regression analysis findings shown in Table 10, one can see that the model was found statistically significant for the differences between the two points in time. The explained variation is $33 \%[F(9,64)$ $=3.49, p<0.001]$. The values of the standardized regression coefficients $(\beta)$ of the differences between the two points in time indicate that the contribution of emotional intelligence capabilities was statistically significant and had the strongest influenceon academic self-efficacy.

According to the unstandardized regression coefficients, one can see that there was a positive correlation between emotional intelligence and academic self-efficacy, such that the higher the emotional intelligence the higher the academic self-efficacy.

In an effort to understand the components of emotional intelligence predicting the sense of academic self-efficacy as a result of participation in the STIC course, an additional regression analysis was executed. Into this analysis were entered the components of the variable emotional intelligence: 1) appraisal and expression; 2) regulation of emotions; and 3) utilization of emotions. It was found at the first point in time, before beginning the program, that the ability to adjust and manage emotions was related to students' ability to adjust their emotions within the framework of their studies. At the second point in time, at the end of the program, it was found that the ability to identify emotions (emotional intelligence 2) made a significant contribution to the development of a sense of academic self-efficacy among students. The data for the differences among the students who participated in the program yielded a similar result. From the study of the regression analysis findings shown in Table 11, one can see that the model was found statistically significant before intervention with an explained variation of $32 \%[F(11,74)=3.13, p<0.001]$. The values of the standardized regression coefficients $(\beta)$ before the intervention process demonstrate that the contribution of the capabilities of emotional intelligence 3 was statistically significant and made the most significant contribution to the development of academic self-efficacy.

According to the unstandardized regression coefficients, one can see that there was a positive correlation 
Table 8. Regression analysis findings for predicting academic self-efficacy before participating in the marathon using the variables emotional intelligence, coping strategies, avoidant coping strategies, and admissions scores.

\begin{tabular}{|c|c|c|c|c|}
\hline \multicolumn{5}{|c|}{ Before: Academic self-efficacy } \\
\hline Variables & B & SE B & B & $\mathrm{T}$ \\
\hline Emotional intelligence & 0.50 & 0.14 & 0.45 & 3.53 \\
\hline Coping strategies & 0.11 & 0.08 & 0.19 & 1.41 \\
\hline Avoidant coping strategies & -0.05 & 0.06 & -0.09 & -0.82 \\
\hline Admissions scores & 0.00 & 0.00 & -0.05 & -0.49 \\
\hline $\mathrm{R}^{2}$ & \multicolumn{4}{|c|}{0.29} \\
\hline $\mathrm{F}$ & \multicolumn{4}{|c|}{$3.39^{* *}$} \\
\hline
\end{tabular}

${ }^{*} p<0.05,{ }^{* *} p<0.01,{ }^{* * *} p<0.001$.

Table 9. Regression findings for predicting academic self-efficacy after participating in the marathon, using the variables emotional intelligence, coping strategies, avoidant coping strategies, and admissions scores.

\begin{tabular}{ccccc}
\hline & After: Academic self-efficacy & & & \\
\hline Variables & $\mathrm{B}$ & $\mathrm{SE}$ B & $\mathrm{B}$ & $\mathrm{T}$ \\
Emotional intelligence & 0.47 & 0.12 & 0.50 & 3.8 \\
Coping strategies & 0.17 & 0.08 & 0.25 & 2.26 \\
Avoidant coping strategies & 0.02 & 0.06 & 0.03 & 0.29 \\
Admissions scores & -0.00 & 0.00 & -0.24 & -2.49 \\
$\mathrm{R}^{2}$ & & & & \\
$\mathrm{~F}$ & & & & \\
${ }^{*} p<0.0 .51$ & & &
\end{tabular}

Table 10. Regression analysis findings for predicting academic self-efficacy-the difference, using the variables emotional intelligence, coping strategies, avoidant coping strategies, and admissions scores.

\begin{tabular}{|c|c|c|c|c|}
\hline \multicolumn{5}{|c|}{ Difference-Academic self-efficacy } \\
\hline Variables & B & SE B & B & $\mathrm{T}$ \\
\hline Emotional intelligence & 0.50 & 0.13 & 0.44 & 3.78 \\
\hline Coping strategies & 0.13 & 0.09 & 0.22 & 1.54 \\
\hline Avoidant coping strategies & 0.07 & 0.07 & -0.11 & -0.94 \\
\hline Admissions scores & 0.00 & 0.00 & -0.17 & -1.46 \\
\hline $\mathrm{R}^{2}$ & \multicolumn{4}{|c|}{0.33} \\
\hline $\mathrm{F}$ & \multicolumn{4}{|c|}{$3.49^{* * *}$} \\
\hline
\end{tabular}

${ }^{*} p<0.05,{ }^{* *} p<0.01,{ }^{* * *} p<0.001$.

between emotional intelligence 3 and academic self-efficacy, such that the higher the emotional intelligence the higher the academic self-efficacy.

From the study of the regression analysis findings shown in Table 12, at the second point in time, one can see that the model was found statistically significant with a variation of $52 \%[\mathrm{~F}(11,69)=6.81, p<0.001]$. The values of the standardized regression coefficients $(\beta)$ after the intervention process demonstrate that the contribution of both the variable emotional intelligence 2 and the variable admissions score was statistically significant. The most significant variable, however, for the development of academic self-efficacy was emotional intelligence 2.

According to the unstandardized regression coefficients, one can see that there was a positive correlation between emotional intelligence 2 and academic self-efficacy, such that the higher the emotional intelligence the higher the academic self-efficacy. In addition, there was a negative correlation between admissions score and academic self-efficacy, such that the higher the admissions score the lower the academic self-efficacy. 
From the study of the regression analysis findings shown in Table 13, one can see that the model was found statistically significant for the differences between the two points in time with an explained variation of $34 \%$ [ $F$ $(11,62)=2.92, p<0.001]$. The values of the standardized regression coefficients $(\beta)$ at the differences between the two points in time demonstrate that the contribution of the variable emotional intelligence 2 was statistically significant and had the greatest influence onacademic self-efficacy.

Table 11. Regression analysis findings for predicting academic self-efficacy-before, using the variables coping strategies, emotional intelligence 1, 2, 3, avoidant coping strategies, and admissions scores.

\begin{tabular}{ccccc}
\hline & \multicolumn{7}{c}{ Before-Academic self-efficacy } & & \\
\hline Variables & $\mathrm{B}$ & $\mathrm{SE} \mathrm{B}$ & $\mathrm{B}$ & $\mathrm{T}$ \\
Emotional intelligence 1 & 0.01 & 0.12 & 0.01 & 0.05 \\
Emotional intelligence 2 & 0.22 & 0.13 & 0.24 & 1.70 \\
Emotional intelligence 3 & 0.29 & 0.13 & 0.34 & 2.18 \\
Coping strategies & 0.09 & 0.08 & 0.15 & 1.13 \\
Avoidant coping strategies & -0.03 & 0.06 & -0.06 & -0.52 \\
Admissions scores & 0.00 & 0.00 & 0.00 & -0.01 \\
$\mathrm{R}^{2}$ & & & 0.32 & \\
$\mathrm{~F}$ & & & $3.13^{* *}$ & \\
\hline
\end{tabular}

${ }^{*} p<0.05, \stackrel{* *}{p}<0.01, \stackrel{* * *}{p}<0.001$.

Table 12. Regression analysis findings for predicting academic self-efficacy-after, using the variables emotional intelligence 1, 2, 3, coping strategies, avoidant coping strategies, and admissions score.

\begin{tabular}{ccccc}
\hline & After-Academic self-efficacy & & & \\
\hline Variables & $\mathrm{B}$ & $\mathrm{SE} \mathrm{B}$ & $\beta$ & $\mathrm{T}$ \\
Emotional intelligence 1 & 0.02 & 0.13 & 0.02 & 0.17 \\
Emotional intelligence 2 & 0.29 & 0.13 & 0.35 & 2.23 \\
Emotional intelligence 3 & 0.18 & 0.13 & 0.22 & 1.37 \\
Coping strategies & 0.13 & 0.08 & 0.19 & 1.64 \\
Avoidant coping strategies & 0.03 & 0.07 & 0.05 & 0.45 \\
Acceptance grades & -0.00 & 0.00 & -0.22 & -2.31 \\
$\mathrm{R}^{2}$ & & & 0.52 & \\
$\mathrm{~F}$ & & & & \\
\hline
\end{tabular}

${ }^{*} p<0.05,{ }^{* *} p<0.01,{ }^{* * *} p<0.001$.

Table 13. Regression analysis findings for predicting academic self-efficacy — difference, using the variables emotional intelligence 1, 2, 3, coping strategies, avoidant coping strategies, and admissions score.

\begin{tabular}{ccccc}
\hline \multicolumn{7}{c}{ Difference-Academic self-efficacy } & & \\
\hline Variables & B & SE B & $\beta$ & T \\
Emotional intelligence 1 & 0.05 & 0.16 & 0.05 & 0.33 \\
Emotional intelligence 2 & 0.30 & 0.15 & 0.30 & 1.96 \\
Emotional intelligence 3 & 0.15 & 0.13 & 0.17 & 1.13 \\
Coping strategies & 0.14 & 0.09 & 0.23 & 1.60 \\
Avoidant coping strategies & -0.06 & 0.07 & -0.10 & -0.85 \\
Acceptance grades & 0.00 & 0.00 & -0.20 & -1.64 \\
$\mathrm{R}^{2}$ & & & 0.34 & \\
$\mathrm{~F}$ & & & $2.92^{* *}$ & \\
\hline
\end{tabular}

${ }^{*} p<0.05,{ }^{* *} p<0.01,{ }^{* * *} p<0.001$. 
Table 14. Comparison of attrition rates for all first-year college students to first-year students who participated in the marathons.

\begin{tabular}{ccccc}
\hline Year & Total attrition from academic institution & \multicolumn{2}{c}{ Attrition for students participating in marathons } \\
\hline & Number & $\%$ & Number & \% \\
2012 & 200 & $7.1 \%$ & 19 & $\mathbf{3 . 0 \%}$ \\
2013 & 260 & $7.8 \%$ & 17 & $\mathbf{2 . 5 \%}$ \\
2014 & 310 & $7.5 \%$ & 21 & $\mathbf{3 . 2 \%}$ \\
\hline
\end{tabular}

According to the unstandardized regression coefficients, one can see that there was a positive correlation between emotional intelligence 2 and academic self-efficacy, such that the higher the emotional intelligence the higher the academic self-efficacy.

At the end of each academic year, attrition rates are recorded for each academic department according to student admissions scores. The findings in Table 14 show that the attrition rate for students who participated in the STIC program was $3.2 \%$ while the rate for students in the same range of admissions scores who did not participate in the program was $7.5 \%$. The attrition rates for both groups of students are presented for two additional years prior to the current study.

This study examined the changes in higher education student academic self-efficacy throughout an intervention process of "marathons", short-term intervention discipline courses in preparation for final examinations (STIC). The hypothesis was twofold: 1) that academic self-efficacy will increase throughout STIC intervention and will be associated with a change in emotional intelligence, use of coping strategies, and use of avoidant coping strategies, and admissions scores and year of study and 2) that attrition rates will drop for students participating in the STIC program.

The most significant finding arising from participation in the marathons was the decrease in use of avoidant coping strategies by the students. Avoidant coping is one of two coping strategies, and is related to the attempt to reduce the source of pressure through distancing oneself from the cause of stress (Lazarus \& Folkman, 1984). This finding repeated itself for $1^{\text {st }}$ and $2^{\text {nd }}$ year students (the primary research population) and in the context of student admissions data. The drop in use of avoidant coping strategies can be explained in light of personal and interpersonal processes. In a short time period, students are confronted and must cope with evaluation and measurement of their academic performance, which require skills such as coping with pressures andformalizing different alternatives for action (Lazarus \& Folkman, 1984). This is an adjustment to the process of coping with problems, involving the need to control emotions in order to cope with the academic challenges (Scott, 1998). The decrease in use of avoidant coping strategies may have resulted from belonging to a peer group studying together under professional guidance, and coping with similar experiences with the course material presented in the STIC exercises. It seems that the drop in use of avoidant coping strategies among students in the $2^{\text {nd }}$ year may be explained by the attempt to repeat success. Students who experienced academic success after participating in the marathons in their first year requested to participate again in their second year (Greenberg, 2013; Schechter, Sykes, \& Rosenfeld, 2008).

The variable of decrease in use of avoidant coping strategies repeated itself in relation to the admissions data for candidates with admissions scores between 501 - 550 and 601 - 650. The improvement among students in the first group can be explained by the fact that their encounter with academic studies and its unique difficulties awakens them to search for coping mechanisms when the small group learning process enables them to do so. In relation to the group with admissions scores from 601 - 650, it appears that the experiences of small group learning and of intimacy increase their abilities for coping. Similarly, the learning that improves the sense of academic self-efficacy of students in the small group contributes to the improvement in coping, which develops alongside improvement in student self-efficacy.

In addition, a decrease in the sense of academic self-efficacy was found among students with low admissions scores and among students with the highest admissions scores. The decrease in the sense of academic self-efficacy among the highest ranking group and the lowest ranking group may stem from the characteristics of the learning support program that are different from routine academic learning. In the support program (STIC), students experience intensive learning within a short time period, which is in contrast to the gradual learning process that is characteristic of academic learning. Academic self-efficacy, in particular, formulates over a gra- 
dual learning process that occurs in reciprocal relation to one's environment, motivation and actual achievements (Bandura, 1994).

The decrease in the sense of academic self-efficacy of the group with the lowest admissions scores can be explained by the Self-Discrepancy Theory of Edward Tory Higgins (Higgins, 1989). According to this theory, the self-image of the individual is influenced by the measure of the gap between actual self and between self-guides, the ideal self and the ought self. The actual self relates to the way in which students perceive their academic abilities after participating in the learning group and before the exam. Self-gaps express the lack of correlation between the actual self and the ought self (Higgins, 1989). The decrease in the sense of academic self-efficacy of the group with the highest admissions scores can be explained as the result of exposure to the group of students with the lowest admissions scores, and the learning methods and difficulties that arose in the small groups with which they worked in the support program. Apparently, there exists an influence resulting from the extent of the gap between the self with which they arrived to the program and the reality in which they learned in the program framework (Higgins, 1989). The increase in the remaining groups in the sense of academic self-efficacy can be explained as the outcome of a program focused on improving academic skills and the creation of experiences of success acquired during a short-term program (STIC) (Barrera, Sandler, \& Ramsay, 1981).

The sense of academic self-efficacy also was examined in the context of emotional intelligence. Emotional intelligence can shed light upon the conduct of the individual in stressful situations and the level of functioning displayed in those situations. The research findings demonstrate that in the 3rd year there began an increase in emotional abilities in accordance with the theory of Mayer and Salovey (1997). According to Mayer and Salovey, emotional intelligence is understood as acting upon emotional information that relates to the meaning of feelings and coping with them, as well as evaluating situations and sets of relationships. Examination of the variables for predicting the sense of academic self-efficacy before participation in the program demonstrates that emotional intelligence was the most significant predictor. Additional analysis shows that the third component of emotional intelligence, relating to the ability of the individual to manage his or her feelings, was the most significant predictor. At the second point in time, after the marathons, the variable E1 was shown to be the most significant predictor, after which was the ability to cope with stress. This can be explained by the connection between the two variables described by Mayer and Salovey (1997), that the abilities of self-regulation and self-management enable coping abilities. It is possible that the component of emotional regulation that was found to be high before the marathon was rerouted to coping abilities after the marathon. Findings show that emotional intelligence was the most significant contributor for predicting a sense of academic self-efficacy among students. It increased at both points in time, before and after the marathons, and in the score of the variation.

From the findings it arises that following the intervention, two additional predictors were added, the ability of the student to cope with the stresses of learning and admissions scores (a combination of psychometric and matriculation exam grades).Within the context of coping ability, problem-focused coping style contributed to the development of the sense of academic self-efficacy. From prior findings of reduced attrition rates we know that $\mathrm{EI}$ is the greatest predictor of academic success. The findings demonstrating significant reduction in attrition rate for students who participated in the STIC program compared to students with the same range admissions scores who did not participate, confirm both the importance of increasing emotional intelligence capability and the efficacy of the STIC model.

\section{Conclusion}

This study teaches about the influence of a short-term model of learning support (STIC) on the development of the sense of academic self-efficacy, use of coping strategies and use of avoidant coping strategies among students taking final examinations. The research findings demonstrate that the STIC model not only advanced the use of coping strategies, it even influenced the reduction of the use of avoidant coping strategies. The latter is seen principally among first-year students with the lowest admissions scores and hence the use of the model can increase their chances for success in academia. Furthermore, the pre-exam intensive learning courses influenced not only academic achievement, but also the development of personality components that advance learning success in higher education. As the examination period approaches, students are forced to cope with many learning tasks. The STIC model contributed to students both in the context of success with the learning challenges given them and with adjusting to the stressful situations they faced during this period.

The research shows that emotional intelligence has influence on the development of academic self-efficacy 
among students. It is apparent that personal support during the first academic year that advances development of personality dimensions such as emotional intelligence and development of the sense of academic self-efficacy among students influences the sense of academic self-efficacy of students and even advances the use of coping strategies in a conscience way among these students.

The central expertise of the STIC course instructors is their academic field. The findings show that training the instructors in the areas of emotional intelligence, academic self-efficacy and coping strategies, will contribute to their ability to further the development of these personality dimensions among students and increase the effectiveness of the STIC model and prevent attrition.

The influence of the STIC model of intervention is on the sense of academic self-efficacy of students; it is the influence of emotional intelligence as a significant social tool. The research sample included students from years 1 - 3 of academic study; however, the relatively small number of third-year students participating makes it difficult to understand the influence of the STIC model on this group. The research sample did not include an equal number of students from the different academic departments; hence, it was decided to carry out a separate analysis for each department. Increasing the sample size of students participating in the research will enable better understanding of the influence of the model both on different academic departments and third-year students.

Higher education reform in Israel leading to the opening of academic institutions to previously excluded populations of students places new challenges before these institutions whose essence is academic support and advancing the success of the new student groups. The influence of higher education on employment capability and future earnings of these young adults makes evident the meaning of success in academia. It strengthens the significance of learning support, particularly for this group of students, whose academic achievement will advance processes of economic, employment and social mobility. The modest contribution of this article is the exposure of the unique working model for academic support before final examinations in higher education. Many institutions give long-range support to students who have difficulty with their studies. This research teaches that short-term support whose central purpose is intensive learning in preparation for exams, and that is carried out in small groups taught by experienced teachers, has significant influence on the success of students. The influence of these courses touches upon the areas of development of emotional intelligence, the sense of academic self-efficacy and the advance of coping strategies among students.

\section{References}

Bandura, A. (1986). Social Foundations of Thought and Action: A Social Cognitive Theory. Englewood Cliffs, NJ: Prentice Hall.

Bandura, A. (1991). Social Cognitive Theory of Self-Regulation. Organizational Behavior and Human Decision Processes, 50, 248-287. http://dx.doi.org/10.1016/0749-5978(91)90022-L

Bandura, A. (1994). Self-Efficacy. In V. S. Ramachaudran (Ed.), Encyclopedia of Human Behavior, (pp. 71-81). New York: Academic Press.

Bandura, A. (1997). Self-Efficacy: The Exercise of Control. New York: W.H. Freeman \& Company.

Bandura, A. (2006). Adolescent Development from an Agentic Perspective. In F. Pajares, \& T. Urdan (Eds.), Self-Efficacy Beliefs of Adolescents, (pp.1-43). Greenwich, CT: Information Age.

Bandura, A., Caprara, G. V., Barbaranelli, C., Gerbino, M., \& Pastorelli, C. (2003). Role of Affective Self-Regulatory Efficacy in Diverse Spheres of Psychosocial Functioning. Child Development, 74, 769-782. http://dx.doi.org/10.1111/1467-8624.00567

Barrera, M., Sandler, I. N., \& Ramsay, T. B. (1981). Preliminary Development of a Scale of Social Support: Studies on College Students. American Journal of Community Psychology, 9, 435-447. http://dx.doi.org/10.1007/BF00918174

Bates, R., \& Khasawneh, S. (2007). Self-Efficacy and College Students’ Perceptions and Use of Online Learning Systems. Computers in Human Behavior, 23, 175-191. http://dx.doi.org/10.1016/j.chb.2004.04.004

Brackett, M. A., \& Mayer, J. D. (2003). Convergent, Discriminant, and Incremental Validity of Competing Measures of Emotional Intelligence. Personality \& Social Psychology Bulletin, 29, 1147-1158. http://dx.doi.org/10.1177/0146167203254596

Brackett, M. A., Rivers, S. E., \& Salovey, P. (2011). Emotional Intelligence: Implications for Personal, Social, Academic, and Workplace Success. Social and Personality Psychology Compass, 5, 88-103. http://dx.doi.org/10.1111/j.1751-9004.2010.00334.x

Britner, S. L., \& Pajares, F. (2006). Sources of Science Self-Efficacy Beliefs of Middle School Students. Journal of Research in Science Teaching, 43, 485-499. http://dx.doi.org/10.1002/tea.20131 
Buck, R. (1984). The Physiological Bases of Nonverbal Communication. In W. Waid (Ed.), Sociophysiology (pp. 139-161). New York: Springer. http://dx.doi.org/10.1007/978-1-4612-5202-3_6

Cervone, D., Kopp, D. A., Schaumann, L., \& Scott, W. D. (1994). Mood, Self-Efficacy, and Performance Standards: Lower Moods Induce Higher Standards for Performance. Journal of Personality and Social Psychology, 67, 499-512. http://dx.doi.org/10.1037/0022-3514.67.3.499

Chan, D. W. (2004). Perceived Emotional Intelligence and Self-Efficacy among Chinese Secondary School Teachers in Hong Kong. Personality and Individual Differences, 36, 1781-1795. http://dx.doi.org/10.1016/j.paid.2003.07.007

Damasio, A., \& Carvalho, G. B. (2013). The Nature of Feelings: Evolutionary and Neurobiological Origins. Nature Reviews Neuroscience, 14, 143-152. http://dx.doi.org/10.1038/nrn3403

Denham, S. A., Blair, K. A., DeMulder, E., Levitas, J., Sawyer, K., Auerbach-Major, S., \& Queenan, P. (2003). Preschool Emotional Competence: Pathway to Social Competence? Child Development, 74, 238-256. http://dx.doi.org/10.1111/1467-8624.00533

Eisenberg, N., Fabes, R. A., Guthrie, I. K., \& Reiser, M. (2000). Dispositional Emotionality and Regulation: Their Role in Predicting Quality of Social Functioning. Journal of Personality and Social Psychology, 78, 136-157. http://dx.doi.org/10.1037/0022-3514.78.1.136

Ekman, P. (1973). Darwin and Facial Expression: A Century of Research in Review. New York: Academic Press.

Elfenbein, H. A., Marsh, A. A., \& Ambady, N. (2002). Emotional Intelligence and the Recognition of Emotion from Facial Expressions. In L. F. Barrett, \& P. Salovey (Eds.), The Wisdom in Feeling: Psychological Processes in Emotional Intelligence (pp. 37-59). New York: Guilford Press.

Feldman, R. S., Philippot, P., \& Custrini, R. J. (1991). Social Competence and Nonverbal Behavior. In R. S. Feldman, \& B. Rime (Eds.), Fundamentals of Nonverbal Behaviour (pp. 329-520). New York: Cambridge University Press.

Fenollar, P., Román, S., \& Cuestas, P. (2007). University Students’ Academic Performance: An Integrative Conceptual Framework and Empirical Analysis. British Journal of Educational Psychology, 77, 873-891.

http://dx.doi.org/10.1348/000709907X189118

Folkman, S., \& Lazarus, R. S. (1986). Stress Processes and Depressive Symptomatology. Journal of Abnormal Psychology, 95, 107-113. http://dx.doi.org/10.1037/0021-843X.95.2.107

Folkman, S., \& Moskowitz, J. T. (2004). Coping: Pitfalls and Promise. The Annual Review of Psychology, 55, 745-774. http://dx.doi.org/10.1146/annurev.psych.55.090902.141456

Greenberg, Z. (2013). The Influence of the "Learning from Success” Method on the Feeling of Self-Capability and Motivation for Success among Special Admissions College Students. Journal of Educational and Social Research, 3, 389-400. http://dx.doi.org/10.5901/jesr.2013.v4n3p389

Higgins, E. T. (1989). Self-Discrepancy Theory: What Patterns of Self-Beliefs Cause People to Suffer? In L. Berkowitz (Ed.), Advances in Experimental Social Psychology (pp. 93-136). New York: Academic Press.

Hochschild, A. (1983). The Managed Heart: Commercialization of Human Feeling. Berkeley, CA: University of California Press.

Hutchison, M. A., Follman, D. K., Sumpter, M., \& Bodner, G. M. (2006). Factors Influencing the Self-Efficacy Beliefs of First-Year Engineering Students. Journal of Engineering Education, 95, 39-47. http://dx.doi.org/10.1002/j.2168-9830.2006.tb00876.x

Keltner, D., \& Haidt, J. (2001). Social Functions of Emotions. In T. Mayne, \& G. A. Bonanno (Eds.), Emotions: Current Issues and Future Directions (pp. 192-213). New York: Guilford Press.

Keltner, D., \& Kring, A. M. (1998). Emotion, Social Function, and Psychopathology. Review of General Psychology, 2, 320342. http://dx.doi.org/10.1037/1089-2680.2.3.320

Kremenitzer, J. (2005). Emotional Intelligence in Teacher Education. Focus on Teacher Education, 5, 6-7.

Lazarus, R. S. (1991). Emotion and Adaptation. New York: Oxford University Press.

Lazarus, R. S., \& Folkman, S. (1984). Stress, Appraisal, and Coping. New York: Springer.

Liem, A. D., \& Nie, Y. (2008). Values, Achievement Goals, and Individual-Oriented and Social-Oriented Achievement Motivations among Chinese and Indonesian Secondary School Students. International Journal of Psychology, 43, 898-903. http://dx.doi.org/10.1080/00207590701838097

Lyons, O. T., Smith, C., Winston, J. S., Geranmayeh, F., Behjati, S., Kingston, O., \& Pollara, G. (2010). Impact of UK Academic Foundation Programmes on Aspirations to Pursue a Career in Academia. Medical Education, 44, 996-1005. http://dx.doi.org/10.1111/j.1365-2923.2010.03787.x

Malach-Fines, A. (1984). The Nature of Emotional Burn-Out and Methods for Coping with It. Tel Aviv: Tcherikover Publications. (In Hebrew) 
Mayer, J. D., \& Salovey, P. (1997). What Is Emotional Intelligence? In P. Salovey, \& D. Sluyter (Eds), Emotional Development and Emotional Intelligence: Implications for Educators (pp. 3-31). New York: Basic Books.

Mayer, J. D., Roberts, R. D., \& Barsade, S. G. (2008). Human Abilities: Emotional Intelligence. The Annual Review of Psychology, 59, 507-536. http://dx.doi.org/10.1146/annurev.psych.59.103006.093646

Mayer, J. D., Salovey, P., \& Caruso, D. R. (2000). Models of Emotional Intelligence. In R. J. Sternberg (Ed.), Handbook of Intelligence (pp. 396-420). Cambridge: Cambridge University Press. http://dx.doi.org/10.1017/CBO9780511807947.019

Morris-Rothschild, B. K., \& Brassard, M. R. (2006). Teachers’ Conflict Management Styles: The Role of Attachment Styles and Classroom Management Efficacy. Journal of School Psychology, 44, 105-121. http://dx.doi.org/10.1016/j.jsp.2006.01.004

Navarrete, S., Candia, R., \& Puchi, R. (2013). Factors Associated with the Dropout/Retention of Mapuche Students of Universidad de la Frontera and the Impact of Academic Support Programs. Calidad en la Educación, 39, 43-80. http://dx.doi.org/10.4067/S0718-45652013000200003

Nowicki, S., \& Duke, M. P. (1994). Individual Differences in the Nonverbal Communication of Affect: The Diagnostic Analysis of Nonverbal Accuracy Scale. Journal of Nonverbal Behavior, 18, 9-35. http://dx.doi.org/10.1007/BF02169077

Owen, S. V., \& Froman, R. D. (1988). Development of a College Academic Self-Efficacy Scale. Proceedings of the Annual Meeting of the National Council on Measurement in Education, New Orleans.

Paul, G., Hinman, G., Dottl, S., \& Passon, J. (2009). Academic Development: A Survey of Academic Difficulties Experienced by Medical Students and Support Services Provided. Teaching and Learning in Medicine, 21, 254-260. http://dx.doi.org/10.1080/10401330903021041

Phan, H. P. (2012). The Development of English and Mathematics Self-Efficacy: A Latent Growth Curve Analysis. The Journal of Educational Research, 105, 196-209. http://dx.doi.org/10.1080/00220671.2011.552132

Salovey, P., \& Mayer, J. D. (1989).Emotional Intelligence. Imagination, Cognition and Personality, 9, $185-211$. http://dx.doi.org/10.2190/DUGG-P24E-52WK-6CDG

Savage, C. R. (2002). The Role of Emotion in Strategic Behavior: Insights from Psychopathology. In L. F. Barrett, \& P. Salovey (Eds.), The Wisdom in Feeling (pp. 211-236). New York: Guilford Press.

Schechter, C., Sykes, I., \& Rosenfeld, J. (2008). Learning from Success as Leverage for School Learning: Lessons from a National Programme in Israel. International Journal of Leadership in Education, 11, 301-318. http://dx.doi.org/10.1080/13603120701576274

Schunk, D. H. (1987). Self-Efficacy and Cognitive Achievement. Proceedings of the 95th Annual Convention of the American Psychological Association, New York, August 28-September 11987.

Schutte, N. S., Malouff, J. M., Hall, L. E., Haggerty, D. J., Cooper, J. T., Golden, C. J., \& Dornheim, L. (1998). Development and Validation of a Measure of Emotional Intelligence. Personality and Individual Differences, 25, 167-177. http://dx.doi.org/10.1016/S0191-8869(98)00001-4

Scott, P. (1998). Massification, Internationalization and Globalization. In P. Scott (Ed.), The Globalization of Higher Education (pp. 108-129). Buckingham: The Society for Research into Higher Education/Open University Press.

Selye, H. (1974). Stress without Distress. Philadelphia, PA: Lippincott.

Selye, H. (1976). The Stress of Life (Revised ed.). New York: McGraw-Hill.

Sternberg, R. J. (2010). College Admissions for the 21st Century. Cambridge, MA: Harvard University Press.

Sternberg, R. J. (2012). The Triarchic Theory of Successful Intelligence. In D. P. Flanagan, \& P. L. Harrison (Eds.), Contemporary Intellectual Assessment: Theories, Tests, and Issues (3rd ed., pp. 156-177). New York: Guilford Press.

Sternberg, R. J., Gabora, L., \& Bonney, C. R. (2012).Introduction to the Special Issue on College and University Admissions. Educational Psychologist, 47, 1-4. http://dx.doi.org/10.1080/00461520.2011.639652

Sutton, R. E., \& Wheatley, K. F. (2003). Teachers' Emotions and Teaching: A Review of the Literature and Directions for Future Research. Educational Psychology Review, 15, 327-358. http://dx.doi.org/10.1023/A:1026131715856

Walsh, C., Larsen, C., \& Parry, D. (2009). Academic Tutors at the Frontline of Student Support in a Cohort of Students Succeeding in Higher Education. Educational Studies, 35, 405-424. http://dx.doi.org/10.1080/03055690902876438

Wigfield, A., \& Eccles, J. S. (2000). Expectancy_Value Theory of Achievement Motivation. Contemporary Educational Psychology, 25, 68-81. http://dx.doi.org/10.1006/ceps.1999.1015

Wintre, M. G., Yaffe, M., \& Crowley, J. (1995). Perception of Parental Reciprocity Scale (POPRS): Development and Validation with Adolescents and Young Adults. Social Development, 4, 129-148.

http://dx.doi.org/10.1111/j.1467-9507.1995.tb00056.x 